\title{
The Effect of the Etymological Elaboration and Rote Memorization on Learning Idioms by Iranian EFL Learners
}

\author{
Iraj Noroozi \\ Islamic Azad University of Varamin, Pishva, Iran \\ Hadise Salehi \\ Islamic Azad University, Garmsar Branch, Iran
}

\begin{abstract}
The present research study investigated potential impacts of the etymological elaboration and rote memorization on the learning of the English idioms by Iranian EFL learners. Sixty $(N=60)$ female students of the Iranmehr language school were selected among a total number of 100 based on their performance on a Nelson proficiency test, and were assigned into two groups. Prior to the study an idiom achievement test was administered to the learners in both groups to make sure that they did not know the idioms at the outset. Subsequently, the participants in the experimental group received the idioms with the relevant etymological elaborations, while those in the control group were asked to memorize the same idioms without the etymological elaborations for 15 sessions. An independent samples t-test was used to compare the mean scores of both groups on the posttest. The results revealed that elaboration of idioms was significantly more effective than learning the same idioms by rote memorization.
\end{abstract}

Index Terms-idiom, etymology, rote memorization, EFL

\section{INTRODUCTION}

Idiomaticity has recently attracted considerable attention in linguistics, psycholinguistics, and psychology (Cacciari \& Tabbosi, 1993). In other words, languages contain many formulaic phrases and expressions that every speaker must learn. According to Bobrow \& Bell (1973) and Boers et al. (2004), languages contain many phrases and expressions that every speaker should learn. Because language production concentrates on an ability to string multi-word expressions, people don't seem proficient speakers of the foreign language until they master many idioms that are used in every day discourse.

Weinreich (1969) defined idiom as an expression whose meaning cannot be derived from the meaning of its individual elements. To illustrate, to kick the bucket means to die. As the figurative meaning is not predictable, idioms create language learning problem for all groups of learners. Weinreich (1972) considers idiomaticity as "a phenomenon which may be described as the use of segmentally complex expressions whose semantic structure is not deducible jointly from their syntactic structure and the semantic structure of their components" (p.89). Since gaining proficiency in a foreign language depends on picking up the idiomatic expressions in the everyday language of native speakers, many researchers have centralized their attentions to the idiom studies in recent years.

Learning idioms has been very difficult for the second language learners; nevertheless, we cannot ignore to acquire them, for the fact that they are useful mediums for conveying our meaning. Furthermore, to improve learners` receptive skills alongside their productive skills, educators have to teach the most frequently used idioms to the learners. In spite of the evident difficulties associated with learning idioms, learning large idiomatic expressions is necessary for the foreign language learners.

Therefore, an important concern in EFL learning is seeking and finding a beneficial method of teaching idioms to improve students` learning process. The mastery of idiomatic expressions appears to be one of the most difficult tasks in the learning of a foreign language. Even advanced learners often cannot reach a native-like level of this skill. Thus, it seems to be necessary to find more effective ways to help the learners to get mastery over all aspects of the foreign language they are learning.

Idioms permeate English with specific features and give it astonishing variety so that "avoiding the use of idioms gives language a bookish, stilted, unimaginative tone" (Cooper, 1999, p.86). They help language learners understand English culture, which has its roots in the customs and lifestyle of the English people, and provides an insight into English history (Crystal, 1997).In recent years, some researchers started to focus on idioms which have an etymology, a story behind. According to Boers et al., (2007) "etymological association is likely to call up a mental image of a concrete scene which can be stored in memory alongside the verbal form" (43). 
Boers 2000, Grant 2004, Boers et al., 2004, proved that associating an idiom with etymology has recently become a popular subject. Also he believed etymological elaboration is an effective method for learning idioms. On the other hand, the researchers intend to know how they can boost the effect of this type of elaboration.

In line with the above discussion, the present study aims to determine if there is any statistically significant difference between the effects of etymological elaboration and rote memorization on learning idioms by the Iranian intermediate EFL learners.

\section{REVIEW OF THE LITERATURE}

Idioms are abundant in everyday speech but have not been the subject of much research. Boers (2000) pointed out the results of several studies have demonstrated that learners` familiarity with metaphor of idioms can have a significant effect on vocabulary retention. Idioms are a class of multi-word units "which pose a challenge to our understanding of grammar and lexis that has not yet been fully met" (Fellbaum, 2006, p. 349). Current psycholinguistic views support the argument in favor of considering idiom as a type of "long word" whose meaning is accessed directly, and not through prior decomposition or analysis of the constituents. On the other hand, when an idiom is encountered for the very first time, language users have no choice but to decipher its meaning from the meaning of the constituents, usually doing so by taking into account the most salient, or prominent, meanings first (Giora, 1997; Peleg \& Giora 2000). It is worth noting that, as with all figurative language, even transparent idioms pose problems for language learners who, lacking the necessary linguistic and cultural knowledge to decipher them, are apt to interpret them literally.

Fernando \& Flavell, (1981) believed traditionally, one of the most important principles for categorizing idioms has been its non-compositional nature. It is believed that its meaning cannot be inferred by adding up the individual elements. As a result, the meaning of idioms seems to be completely arbitrary. (Cooper, 1999)

Kovecses (1990) proved that a large number of idioms are not quite arbitrary. This means that their figurative meaning of idiomatic expressions is unpredictable on the basis of a figurative meaning.

Grant (2004) believed that only a few entries in idiom dictionaries are non- compositional and non-figurative and therefore it is especially difficult for the learners to process them in an effective way. In contrast to the traditional views in second and_foreign language learning, the majority of idioms could be presented to learners in different ways that go beyond rote learning.

The results of experiments have already been showed the useful effect of presenting idioms to learners semantically. For example, retention has been facilitated by enhancing learners' awareness of the metaphors beyond the figurative expressions (Boers, 2000; Kovescses \& Szabo, 1995). Several studies have also shown students to be more interested in remembering the figurative idioms with their original usage. (Boers, 2001)

Boers (2001) found, a strategy of inferring idiom`s meaning only from its original usage cannot provide a correct interpretation. As it could provide an additional way for learning. In contrast to the "traditional" belief, which believed that the idioms are 'dead' metaphors that could only be learned through memorization, cognitive semantics provides the more systematic way to learn of a large number idiomatic expressions.

The results of many experiments have shown that students` familiarity with the Literal meanings of idioms can have a positive effect on vocabulary retention(Boers 2000).Boers (2000a, 2000b) also identified three dimensions which contribute to this beneficial effect.

1. The conceptual metaphors (i.e. the "metaphoric themes" or "source domains") behind different idioms provide a framework of organization which seems to be quite arbitrary and unsystematic. As organized information is easier to learn than random input, the use of metaphors can facilitate retention.

2. The identification of metaphors behind idioms by learners involves a certain degree of cognitive effort. This process can enhance "in-depth" cognitive processing, which increases memory storage.

3. Learning through imagery processing facilitates the recall. These three dimensions are in fact to enhance vocabulary learning in general.

On the other hand, Moore (2000) defined rote learning as a method involving repetition and memorization.

Rote learning is not only a system which enable the learner to understand the information but also it involves memorizing and storing the incoming information.

Memorization refers to the strategies which focus on the storage and retrieval of language; so some of the strategies, such as drill and repetition, used for practice are the same as memorization strategies. However, in memorization, the main focus is on the storage and retrieval process. The goal of these strategies is organization (Wenden \& Rubin, 1987). It has been found in the researches among language learning strategies, repetition is a strategy which frequently used by L2/FL learners (O’Malley, 1985, Chamot, 1987). It has been proposed in the language learning strategies that memorization involving repetition contributes to the storage and retrieval of language, and there has been an emphasis on the storage and retrieval process (Rubin, 1987).

Ellis and Beaton (1993) suggested memorization and repetition are interchangeably used and both are relevant to RL strategies which consolidate meaning and the form of item English learners use memorization in different ways, starting from learning to deal with exercises (Adamson, 1990, p.76). Almad, an Arab student, used memorization as a strategy of learning new vocabulary. He found all the unknown words, wrote the new word and its meaning in and then 
memorized them. The result is that he learned many words but as a slower reader. Meanwhile, Cook (1994) believes repetition and memorization are two of the most valuable, and uses of language learning activities.

A study on the subject of idiom was done by Baleghizadeh \& Mohammad Bagheri (2012). In order to solve the problem of learning idiom among EFL learners, the researchers used etymological elaboration to facilitate idiom`s learning. To accomplish the purpose of this study, 32 Iranian EFL upper-intermediate students were randomly assigned to two groups, one as control group and one as experimental group. Participants in the experimental group received idioms with the etymological elaborations in short texts, while in the control group, participants received the same idioms without etymological elaboration. The results revealed that etymological elaboration has significant effect on EFL students`comprehension and retention.

Another study was conducted by Boers (2001). This study was done in order to evaluate the effect of using imagery on students retention of figurative idioms. The aim of this study was to see whether these techniques would have significant effect on learners` in associating imageries to new idioms. Students were divided into two groups (experimental group and control group). In both groups, participants were given 10 unknown idioms and were asked to write their meanings. Participants in the control group were asked to provide a context for each idiom, while the participants in the experimental group were asked to provide origin of idioms. The results revealed that the participants in the experimental group were more successful in idioms retention.

\section{METHOD}

\section{Participants}

The participants of this study were 100 Iranian EFL learners studying at the Iranmehr language institute whose ages ranged from 20 to 30. Following the pilot study, a Nelson test was administered based on which 60 female learners were selected to participate in this study. The other forty participants were excluded from the study because of their low language proficiency test scores. Next, 30 participants were randomly placed in one group and the other 30 participants were placed in another namely experimental and control groups. Because the variable of sex has been held constant, no male student was included in this study.

\section{Instruments}

Three tests and four books were utilized to accomplish the purpose of the study.

1. Nelson test as a means of estimating the participants' level of language proficiency. 2. A test of idioms to make sure that the participants were not aware of idioms prior to study. This test served as a pre-test.

3. A different test of idioms was also utilized as the posttest, the results of which were used to verify the hypotheses of the study.

4. Four books: A New Approach to Idioms, Dictionary of the Origins and Stories of English Idioms, Oxford Dictionary of Idioms, and the Dictionary of Idioms and Their Origins were incorporated as the sources for the idioms to be taught. Proficiency test (Nelson Test Battery) In order to have a homogenized sample for the study, a piloted 40-item Nelson test 300C, taken from the intermediate book of Nelson English Language Tests was administered. The time which can be allocated to complete each test is 40-50 minutes. According to Flower and Coe (1976), all items in these tests have been carefully pretested with both students whose native language was usually Spanish and to students from different language backgrounds from all over the world.

\section{Test of idioms}

The test of idioms was made up of 23 translations, 10 fill in the blanks, 12 matching items which were chosen from A New Approach to Idioms by Birjandy and Shahidy (2009) and A Dictionary of the Origins and Stories of English Idioms by Golshan (2009) and Preparation Course for the TOEFL by Phillips (2003) which have been designed in order to meet EFL learners ' need for the most common and handiest English idioms in daily use. The purpose of this test was to make sure that the learners didn't know much about the idioms at the outset of the study. This test was piloted and the result revealed that the reliability calculated through Kuder- Richardson formula 21 was 0.77.

\section{Posttest of Idioms}

To make sure the participants were not affected by the instructions, the researcher administered another test that was different from the pre- test. The test was made up of 33 translations, 25 matching items which were chosen from the aforesaid materials. Treatment Materials The researcher selected 58 idioms from: Oxford Dictionary of Idioms, A New Approach to Idioms (Birjandy and Shahidy, 2009), and A Dictionary of the Origins and Stories of English Idioms (Golshan, 2009). The selected idioms were relevant to the participants` learning experience. Two factors were taken into account to determine this: first, having a connection with the content of the lessons which the students had studied so far, and second, being of interest to them. The teacher was a good source of help for the selection procedure because she was familiar both with the content of the lessons, due to her long teaching experience, and with the students' personality traits.

\section{Procedure}

The intermediate Nelson test was first piloted among a group of 30 female learners, the reliability of this piloting stood at 0.78. Consequently it was confirmed that the test enjoyed high reliability. The researcher administered the revised version among 100 female learners at the intermediate level. 60 learners who scored one standard deviation -/+ 
the mean score were selected to participate in this research Next; they were randomly divided into two groups, that is, the control group and the experimental group.

The participants were all briefed on what the idioms are in the opening sessions. On the first session of each of two classes, the learners in both groups took a pre-test. The results showed that there was no significant difference between the two means of the experimental and control groups on the pretest of Idiomatic knowledge $(\mathrm{t}(58=.54, \mathrm{p}>.05$, it represents a small-sized effect $r=.07$ ). Thus the results indicated that the two groups enjoyed the same level of knowledge on English idioms prior to the administration of the etymological elaboration to the experimental group and the rote memorization to the control group. After completing the test, the idioms were equally instructed for 15 sessions, and each session took about one hour. To clarify, the original usage and etymological hints of idioms were instructed to experimental group, while the control group`s participants were encouraged to learn the idioms without any etymological elaboration. Once the instruction period was over, the researcher conducted the posttest among both the control and experimental groups to check whether there existed any statistically meaningful difference between the participants in both groups because of the treatment.

\section{RESULTS}

In this study, the researchers investigated the impacts of impacts of etymological elaboration and rote memorization on Iranian intermediate EFL learners. After gathering the data, the results were subjected to a series of statistical analysis. to compare the mean scores of the two groups on the posttest of idioms an independent t- test was conducted in order to find which of the two methods of etymological elaboration or rote memorization has a more significant effect on the idiom learning of the Iranian intermediate EFL learners. As displayed in the Table 1 the experimental group $(M=38.57)$ after receiving etymological elaboration outperformed the control group $(M=27.27)$ on the posttest of idioms.

TABLE 1

DESCRIPTIVE STATISTICS FOR POSTTEST OF IDIOMS

\begin{tabular}{|l|l|l|l|l|}
\hline GROUP & $N$ & Mean & Std. Deviation & Std. Error Mean \\
\hline Experimental & 30 & 38.57 & 8.169 & 1.491 \\
\hline Control & 30 & 27.27 & 5.656 & 1.033 \\
\hline
\end{tabular}

The results of the independent t-test indicate that the above mentioned difference between the mean scores of the two groups on the posttest of idioms is statistically significant $(\mathrm{t}(58)=6.22, \mathrm{p}<.05$, it represents a large-sized effect $\mathrm{r}$ $=.63$ ). Thus the first null-hypothesis as there is not any statistically significant difference between the effects of etymological elaboration and rote memorization on idiom learning of the Iranian intermediate EFL learners is rejected. The subjects who received etymological elaboration performed better on the posttest of idioms.

A paired-samples t-test was used in order to probe the effect of etymological elaboration on the improvement of their knowledge on English idioms. Experimental group shows a high improvement on the posttest of idioms $(\mathrm{M}=38.57)$ compared with the pretest $(\mathrm{M}=25.24)$.

TABLE 2

DESCRIPTIVE STATISTICS FOR PRETEST AND POSTTEST OF IDIOMS

\begin{tabular}{|l|l|l|l|l|}
\multicolumn{5}{c}{ (EXPERIMENTAL GROUP) } \\
\hline & Mean & $N$ & Std. Deviation & Std. Error Mean \\
\hline POSTTEST & 38.57 & 30 & 8.17 & 1.49 \\
\hline PRETEST & 25.24 & 30 & 7.18 & 1.31 \\
\hline
\end{tabular}

The results of the paired-samples t-test indicate that the difference is statistically significant $(\mathrm{t}(29)=9.39, \mathrm{p}<.05$, it represents a large=sized effect $r=.86$ ). Thus the second null-hypothesis as etymological elaboration goes not have any statistically significant effect on idiom learning of the Iranian intermediate EFL learners is rejected. The experimental group following the etymological elaboration shows significant improvement on the posttest of idioms.

A paired-samples t-test was conducted to compare the mean scores of the control group on the pretest of idioms in order to probe the effect of rote memorization on the improvement of their knowledge on English idioms. As displayed in Table 3 the control group shows a high improvement on the posttest of idioms $(M=27.27)$ compared with the pretest $(\mathrm{M}=26.3)$.

TABLE 3

DESCRIPTIVE STATISTICS FOR PRETEST AND POSTTEST OF IDIOMS (CONTROL GROUP)

\begin{tabular}{|l|l|l|l|l|}
\multicolumn{5}{c|}{ IDIOMS (CONTROL GROUP) } \\
\hline & Mean & $N$ & Std. Deviation & Std. Error Mean \\
\hline POSTTEST & 27.27 & 30.00 & 5.66 & 1.03 \\
\hline PRETEST & 26.31 & 30.00 & 8.29 & 1.51 \\
\hline
\end{tabular}

The results of the paired-samples t-test indicates that the difference observed in Table 4 is not statistically significant $(\mathrm{t}(29)=1.71, \mathrm{p}<.05$, it represents a medium-sized effect $\mathrm{r}=.30)$. Thus the third null-hypothesis as rote memorization does not have any statistically significant effect on idiom learning of the Iranian intermediate EFL learners is supported. 
Although the control group following the rote memorization shows improvement on the posttest of idioms the difference is not high enough to reject the null-hypothesis.

TABLE 4

PAIRED-SAMPLE T-TEST FOR PRETEST AND POSTTEST OF IDIOMS (CONTROL GROUP)

\begin{tabular}{|c|c|c|c|c|c|c|c|c|}
\hline & \multicolumn{5}{|c|}{ Paired Differences } & \multirow[t]{3}{*}{$\mathrm{T}$} & \multirow[t]{3}{*}{ Df } & \multirow{3}{*}{$\begin{array}{l}\text { Sig. (2- } \\
\text { tailed) }\end{array}$} \\
\hline & \multirow[t]{2}{*}{ Mean } & \multirow{2}{*}{$\begin{array}{l}\text { Std. } \\
\text { Deviation }\end{array}$} & \multirow{2}{*}{$\begin{array}{l}\text { Std. Error } \\
\text { Mean }\end{array}$} & \multicolumn{2}{|c|}{$95 \%$ Confidence Interval of the Difference } & & & \\
\hline & & & & Lower & Upper & & & \\
\hline POSTTEST - PRETEST & 0.95 & 3.05 & 0.56 & -0.19 & 2.09 & 1.71 & 29.00 & 0.10 \\
\hline
\end{tabular}

Reliability Indices

The reliability indices for the Nelson test and pretest and posttest of idioms are $0.78,0.77$ and .84 , respectively.

TABLE 5

K-R21 RELIABILITY INDICES

\begin{tabular}{|l|l|l|l|l|}
\hline Descriptive Statistics & N of Items & Mean & Variance & K-R21 \\
\hline & 50 & 31.72 & 48.56 & .78 \\
\hline NELSON & 58 & 25.7778 & 59.481 & .77 \\
\hline PRETEST & 58 & 32.92 & 80.993 & .84 \\
\hline POSTTEST & &
\end{tabular}

\section{Validity}

The Pearson correlations between the Nelson test and pretest and posttest of idioms are employed as empirical validity indices of the latter two tests. There are statistically significant correlations between the Nelson test and pretest $(\mathrm{r}-.75$, it represents a large-sized effect) and posttest $(\mathrm{r}=.59$, it represents a large-sized effect). Thus it can be claimed that both pretest and posttest of idiom enjoy high empirical validity indices.

TABLE 6

EMPIRICAL VALIDITY

\begin{tabular}{|c|c|c|c|}
\hline & & PRETEST & POSTTEST \\
\hline \multirow{3}{*}{ NLESON } & Pearson Correlation & $.758^{* *}$ & $.593^{* * *}$ \\
\hline & Sig. (2-tailed) & .000 & .000 \\
\hline & $\mathrm{N}$ & 60 & 60 \\
\hline
\end{tabular}

\section{DISCUSSION}

The results revealed the experimental group who received etymological elaborations perform better in learning idioms than the other group. These findings are in line with the recent approaches towards etymological information of an idiom. The results of this study indicate that etymological information improves idiom learning of the students and this finding is consistent with Boers (2004) which stated that the mnemonic effects of etymology to idioms are more than the other techniques. Boers (2001) also said that if idioms which derived from specific source are associated with the original usage will be kept more in the memory of students.

The findings confirm Conceptual Metaphor Theory, which suggests that idioms are not mere strings of words with an arbitrary meaning. Instead, their meaning can be traced back to a concrete scene representing the first source from which the idiom was taken. The findings are in conformity with other studies made in the domain of Conceptual Metaphor Theory and idiom learning. The results obtained via this experiment can be a source of motivation for both teachers and learners to take advantage of etymological awareness to deal with this aspect of language. These results reveal that figurative aspect of many idioms is not arbitrary; rather, there is an origin or story behind many of them, and reviving such stories can be a crucial factor in learning idiom. There is a correlation between this study and findings.

\section{CONCLUSION}

In this study, the researcher investigated the impacts of etymological elaboration and rote memorization on idiom learning. Two groups of participants, experimental and control, received the same set of idioms. The experimental group received the etymology or origins of the idioms, while the control group did not. Following the last session of treatment, their scores were added up and a t-test was conducted to check the differences between them. The results revealed a significant difference between the two groups, that is, the experimental group significantly performed better than the control group in learning idioms.

\section{IMPLICATIONS}

This study revealed that learners` idiom learning increase when the content is taught through an etymological elaboration instruction. This study confirms the etymology in order to teach idioms. English teachers can benefit from 
an etymological elaboration approach in order to teach idioms, which are an important part of language learning. When undergoing the etymological elaboration approach, students enjoy their learning- as was visible for the researcher during her observations of the procedure and was expressed by the learners themselves. This research can help syllabus designers and textbook writers to incorporate etymological elaboration in their products. Since materials which deal with all aspects of idioms are crucial to the learning of idioms, developing such materials is strongly recommended to those who have a hand in material development.

1. Since this study was only conducted on the female participants, a similar research can be done on the opposite sex or both together.

2. A more comprehensive study can be done on larger number of subjects.

3. There is a need to carry out similar experiments to investigate the long-term effects of teaching idioms through different techniques, strategies, activities, and other areas of language similar to idioms such as phrasal verbs and metaphors.

4. Since this study covers only 58 English idioms, a more comprehensive study can be done by employing more idioms.

5. Finally, this study can be performed with learners with different levels of language proficiency.

\section{REFERENCES}

[1] Adamson, H. D. (1990). ESL students` use of academic skills in content courses. English for specific purposes, 40(1), 75-76.

[2] Baleghizadeh, S. \& Mohammad Bagheri, M. (2010). The Effect of etymology elaboration on EFL learners` comprehension and retention. The Southeast Asian Journal of English Language Studies, 18(1), 23-33.

[3] Birjandi, P., \& Shahidy, H., \& Addy, F. (2005). A new approach to idioms, customs, slang. Tehran: Gooyesh Novin Press.

[4] Bobrow, S., \& Bell, S. (1973). On catching on to idiomatic expressions. Memory and Cognition, 1, 343-346.

[5] Boers, F. (2004). Expanding learners` vocabulary through metaphor awareness: what expansion, what learners, what vocabulary? In M. Achard \& S. Niemeier (EDS.), Cognitive linguistics, second language acquisition, and foreign language teaching, 211-232. Berlin: Mouto de Gruyter.

[6] Boers, F. (2000a). Metaphor awareness and vocabulary retention. Applied Linguistics, 21, 553-71.

[7] Boers, F. (2000b). Enhancing metaphoric awareness in specialized reading. English for Specific Purposes, 19, 137-47.

[8] Boers, F. (2001). Remembering figurative idioms by hypothesizing about their origins. Prospect, 16, 35-43.

[9] Boers, F., Demecheleer, M., \& Ekyckmans, J. (2004). Etymological elaboration as a strategy for learning idioms. In Bogaards, P. and Laufer, B., editors, vocabulary in a second language: selection, acquisition and testing, Amesterdam and Philadelphia: John Brnjamins, 53-78.

[10] Cook, G. (1994). Repetition and learning by heart: An aspect of intimate discourse, and its implications. English Language Teaching Journal, 48, 133-139.

[11] Cooper, T. (1999). Processing of idioms by L2 learners of English. TESOLE Quarterly, 33,233-62.

[12] Crystal, D. (1997). English as a Global Language. Cambridge: Cambridge University Press

[13] Ellis, N. \& Beaton, A. (1993). Psychological determinants of foreign language vocabulary learning. Language Learning, 43, 559-617.

[14] Fernando, C. \& Flavell, R. (1981). On idiom: critical views and perspectives. Exeter Linguistic Studies, 5. Exeter: University of Exeter.

[15] Giora, R. (1997). Understanding figurative and literal language. The graded salience hypothesis, Cognitive Linguistic, 7, 183206.

[16] Golshan, M. (2009). A dictionary of the origins and stories of English idioms. Tehran, Jungle Press.

[17] Grant, L. (2004). A corpus-based investigation of idiomatic multiword units. PHD dissertation, Victoria University of Wellington

[18] Kövecses, Z. \& Sazabó, P. (1996). Idioms: a view from cognitive semantics. Applied Linguistics, 17, (3), 326-55.

[19] O`Malley, J., Chomot, A., Stewner-Manzanares, G., Russo, R. \& Kupper, L. (1985). Learning strategy applications with students of English as a second language. TESOL Quarterly 19, 557-584.

[20] Philip, D. (2003). Preparation course for the TOEFL. New York. Pearson Education.

[21] Rubin, J. (1987). Learner strategies: theoretical assumptions, research history and typology in: Wenden, A. \& Rubin. J. (Eds) Learner Strategies in Language Learning .Hempstead: Prentice Hall International

[22] Sökmen, A. (1997). Current trends in teaching second language vocabulary. Description, acquisition and pedagogy. Cambridge: Cambridge University Press.

[23] Weinreich, U. (1996). Problems in the analysis of idioms. In J. Puhvel (ED.), Substance and structure of language. California. Berkeley University of California.

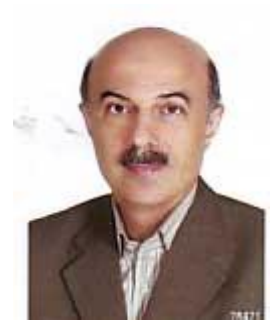

Iraj Noroozi was born in Tehran, Iran in 1955. He obtained his BA in English language translation from Allameh Tabatabaee state university in 1978. Afterwards, he got his MA in language teaching from the Azad University located in Tehran, Iran in 1995. In the long run, he studied for five consecutive years to receive his $\mathrm{PhD}$ in language teaching along with high average from Azad University situated in Tehran, Iran in 2005.

He has been teaching English and French in various institutions, But his main job is in the Azad University as an ASSISTANT PROFESSOR. He has also the command of French and German and speaks these two languages fluently. He has got seven of his books concerning general and specialized language teaching published thus far. He has also presented fifteen of his articles in different universities in Iran along with getting some prizes for some of them. He has conducted three research projects in the area of his specialty- 
that is, language teaching so far. His research interest is in the domain of reading comprehension.

Dr. Noroozi is an official member of the faculty in the Azad University located in Iran. He has been the head of the language department for three years. He has been the head of the college of literature and humanities for three years as well. He has also been selected as the member of the committee select and has been performing his job in this area too. He has been chosen as the best professor in the university for two years, i.e., 2006 and 2012. He has also been selected as the best researcher in his university in 2009.

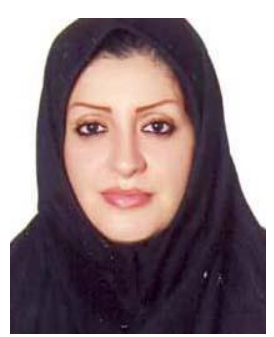

Hadise Salehi was born in Tehran, Iran in 1982. She has obtained her BA In language teaching from Azad University located in Tehran, Iran in 2005.afterwards; she got her MA in language teaching from Azad University located in Garmsar, Iran in 2012.

She started teaching career in different institutes. She has been teaching English for 7 years. She has presented poster in TELLSI conference. Her areas of interest and research include: Sociocultural Theory, Teacher Education, SAL, Second Language Writing, Testing and Assessment. 